\title{
Evaluation of Electric Vehicle Charging Controllability for Provision of Time Critical Grid Services
}

\author{
Martinenas, Sergejus; Marinelli, Mattia; Andersen, Peter Bach; Træholt, Chresten
}

Published in:

Proceedings of the 51st International Universities Power Engineering Conference

Link to article, DOI:

10.1109/UPEC.2016.8113989

Publication date:

2016

Document Version

Early version, also known as pre-print

Link back to DTU Orbit

Citation (APA):

Martinenas, S., Marinelli, M., Andersen, P. B., \& Træholt, C. (2016). Evaluation of Electric Vehicle Charging Controllability for Provision of Time Critical Grid Services. In Proceedings of the 51st International Universities Power Engineering Conference IEEE. https://doi.org/10.1109/UPEC.2016.8113989

\section{General rights}

Copyright and moral rights for the publications made accessible in the public portal are retained by the authors and/or other copyright owners and it is a condition of accessing publications that users recognise and abide by the legal requirements associated with these rights.

- Users may download and print one copy of any publication from the public portal for the purpose of private study or research.

- You may not further distribute the material or use it for any profit-making activity or commercial gain

- You may freely distribute the URL identifying the publication in the public portal 


\title{
Evaluation of Electric Vehicle Charging Controllability for Provision of Time Critical Grid Services
}

\author{
Sergejus Martinenas, Mattia Marinelli, Peter Bach Andersen, Chresten Træholt \\ Center for Electric Power and Energy, Department of Electrical Engineering, DTU - Technical University of Denmark \\ Contact Person: Sergejus Martinenas, smar@elektro.dtu.dk
}

\begin{abstract}
Replacement of conventional generation by more stochastic renewable generation sources leads to reduction of inertia and controllability in the power system. This introduces the need for more dynamic regulation services. These faster services could potentially be provided by the growing number of electric vehicles. EVs are a fast responding energy resource with high availability. This work evaluates and experimentally shows the limits of EV charging controllability with the focus on its suitability for providing ancillary grid services. Three different series produced EVs are tested. The experimental testing is done by using charging current controllability of built-in AC charger to provide a primary frequency regulation service with very dynamic input frequency. The results show that most the controllability of most EVs is more than suitable for providing time critical grid services. Meanwhile, charging current ramping rates of recently produced EVs are potentially suitable to provide synthetic inertia.
\end{abstract}

Keywords - Electric Vehicles, Charging Stations, Power Control, Smart Grid

\section{INTRODUCTION}

Year by year share of renewable generation in the power grid is increasing. This mostly stochastic energy source and lack of directly coupled rotating machines leads to reduced controllability and lower system inertia [1], [2]. This change introduces the need for much faster regulation services. Current grid services are designed to be provided by conventional generation sources, thus timing requirements of these services are adhering to ramping rates of these power plants. Transition to more dynamic grid power flows will require faster regulation services [3].

Simultaneously, the share of fast responding, high availability energy resource - electric vehicles (EVs), is rapidly growing. While EVs are viewed as a solution to the environmental problems in transportation sector they are treated as additional loads that will require grid upgrades in the energy sector. However, with intelligent integration of the EV charging infrastructure they become a potential grid balancing resource [4], [5], [6]. When aggregated in big numbers, vehicles could provide the services including current ancillary services defined by grid operators, as well as ones addressing

This work is supported by the Danish Research Project "NIKOLA Intelligent Electric Vehicle Integration"- under ForskEL kontrakt nr. 20131-12088. More information (www.nikolaproject.info). future issues of the grid, such as defined in NIKOLA project [7], [8]. Service provision is possible by controlling the charging current limit of the build-in EV charger as defined by IEC 61851 standard [9]. However, the response times and precision for EVs of different make or model are not identical even though it is defined by the standard. Depending on the EV model, the speed of EV response can vary from under a second to few seconds. Such difference in timing, although being small, mean that only some vehicles could provide time critical services such as synthetic inertia or very fast frequency regulation. In this work 3 different vehicles of different brand and model are tested for speed of response. This work is mainly focusing on AC charging as DC charging is only meant for quick charging sessions typically not suitable for grid service provision due to short session duration and user comfort. It should be mentioned that vehicle to grid (V2G) technologies could greatly improve the grid service provision [10], however at the time of writing they are still in development phase and are not considered in this work.

The paper is structured as follows: Section II describes potential grid services that EVs could provide. Section III presents the method and experimental test setup used for assessing EV charging controllability. Section IV shows and analyses the results of the experimental validation. Section V summarizes and further discusses the evaluation and potential alternative solutions.

\section{GRID ANCILLARY SERVICES}

This work focuses on evaluating the potential of electric vehicles to provide different grid support services for the current and future smart grid. Therefore the grid service definitions are taken from the Danish Transmission System Operator (TSO) - Energinet.DK ancillary service provision requirements [11] and NIKOLA project service catalog [7]. The examples of grid services considered are primary frequency regulation, very fast frequency regulation, synthetic inertia. All of these services are time critical but have very different response time constrains.

The Danish power grid is uniquely split into two separate synchronous regions: DK1 and DK2. Jylland peninsula and island of Fyn are in DK1 region connected continental part of Europe. The islands of Sjælland and Bornholm are in DK2 connected Nordic synchronous area. 
The definitions of services relevant to primary frequency regulation ancillary service from Energinet.DK:

- Primary Reserve in DK1 region - restores balance between production and consumption, stabilising the frequency at close to, but deviating from $50 \mathrm{~Hz}$. The regulation is automatic and responding to frequency deviation, with a small permitted deadband. The first half of the activated reserve must be supplied within 15 seconds, while the last half must be supplied in full within 30 seconds.

- Normal Operation Reserve in DK2 region - ensures that production and consumption equilibrium is restored. The regulation is automatic and responding to frequency deviation, without dead-band. The reserve must be supplied within 150 seconds.

- Disturbance Reserve in DK2 region - a fast reserve, activated in the event of major system disturbances. It is started automatically in the event of sudden frequency drop under $49.9 \mathrm{~Hz}$ and remains active until frequency is restored or manual reserve takes over. The first $50 \%$ of the response must be supplied within 5 seconds, the remaining $50 \%$ of the response within an additional 25 seconds.

In addition to these services the time critical grid services defined in NIKOLA project:

- Fast Frequency Reserve - the time requirements are very similar to the one specified for the disturbance reserve in DK2, which is already a rather demanding service, but in this case the full reserve is required to be deployed in 10 seconds.

- Synthetic Inertia - the reserve that mimics rotational inertia of the generations. it requires full deployment of the reserve within 1 or 2 seconds. The time is highly influenced by the actual system inertia. The lower is the equivalent inertia of the system, the higher is the time criticality of this service. Moreover, what makes this service even more challenging, is the fact that the equivalent system inertia could change during the day, depending on the amount of inverter driven resources (such as photovoltaic or Type C and D wind turbines) are connected in the system.

It should be noticed that different services have varying response time requirements from milliseconds to tens of seconds. The setup chosen for testing the EV response time is following the guidelines of primary frequency regulation service with simple droop control.

\section{Methodology}

The response time of the of the service is dependent on the whole control loop. In this work a typical control architecture consisting of EV, charging point, control aggregator and grid connection is considered. The experimental test setup is shown in Fig. 1.

The setup consists of the following components:

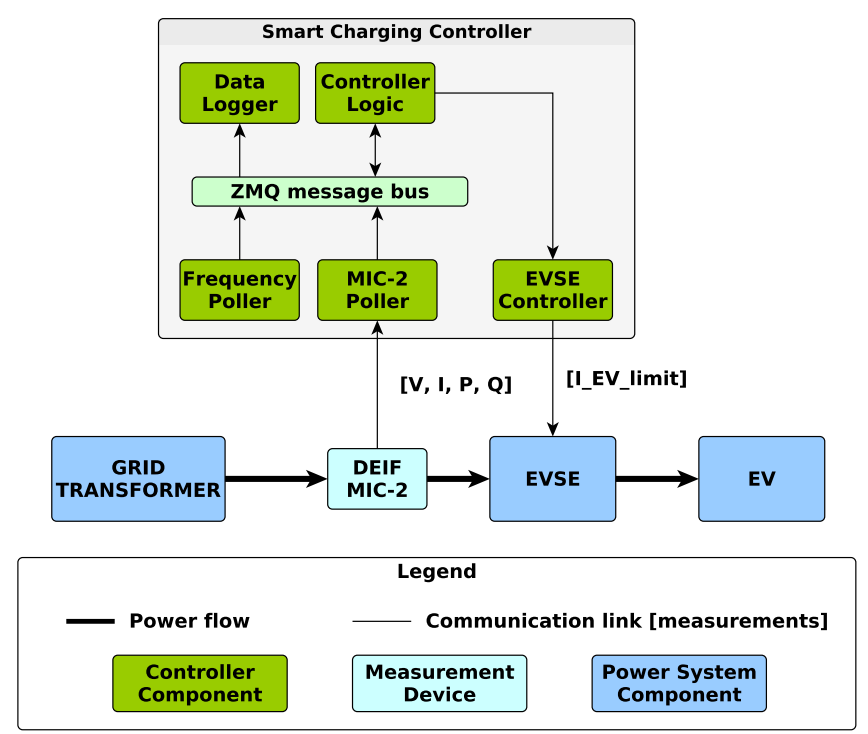

Fig. 1. Experimental test system setup

- Smart charging controller - receives the measurements from the power meter and sends control signals to the EVSE.

- DEIF MIC-2 - multi-instrument measurement device for voltage, current and power measurements with $0.5 \%$ accuracy. The device is polled every 0.2 seconds.

- EVSE - Electric Vehicle Supply Equipment, also known as the charging spot rated for $16 \mathrm{~A}$.

- EV - one of the 3 different electric vehicles tested in this evaluation.

- Grid - grid connection at the SYSLAB experimental facility.

The charging controller consists of many sub-components described here:

- Controller logic - reads the latest frequency measurements from the message bus, calculates the set-points and sends control signals directly to the EVSE controller.

- EVSE controller - acts as an abstraction interface between the physical EVSE and charging controller components.

- Frequency poller - interface to the frequency measurements. Commonly, DEIF MTR-3 measurement instrument would be used for frequency sampling every second with the accuracy of $\pm 10 \mathrm{mHz}$.

- MIC-2 poller - DEIF MIC-2 multi-instrument interface abstracting data collection from the measurement device.

- Data logger - monitors the data on the message bus and $\operatorname{logs}$ it to the database.

- ZMQ message bus - message bus developed for easier data exchange between controller components.

ZeroMQ communication framework [12] used to establish a message bus, this is done to minimize the delay and ease the integration of additional controller components. 
Typically, the slowest part of the whole communicationcontrol loop is the EV power response time [13]. In most modern EVs, communication between a vehicle and a charging point is defined by IEC 61851 standard. The standard states that in case a charging current limit is changed, the vehicle should respond within 3 seconds. Additionally, the standard specifies the lowest current limit is $6 \mathrm{~A}$ with a step of $1 \mathrm{~A}$, while upper current limit is defined by a minimum function of the charging cable and the fuse rating of the EVSE. The charging power adjustment response time and precision of multiple commercially available EVs are compared. The EVs used in the test are Nissan Leaf (2015 model), Peugeot Ion (2011 model) and Renault Kangoo (2012 model). All of these EVs are equipped with $3.3 \mathrm{~kW}$ AC chargers which can be controlled between 6 to $16 \mathrm{~A}$ - providing $2.3 \mathrm{~kW}$ of flexibility window. As the grid frequency from real grid is rather stable, the randomized input frequency was designed that would force the controller to change the set-point at each iteration. The input frequency used in this experimental testing is shown in Fig. 2. This way the controllability of each EV is pushed to the limit and the ramping rates can be assessed.

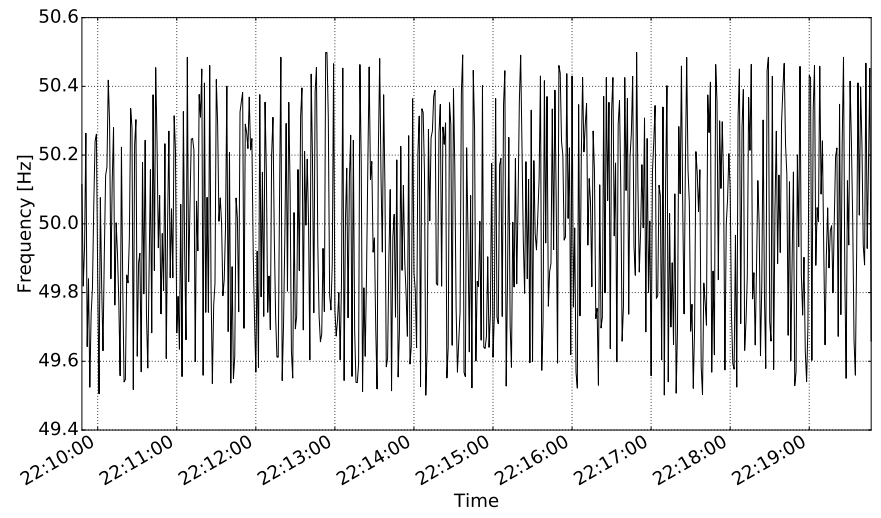

Fig. 2. Input frequency for controller logic

\section{RESUlts}

Here the response of the full control loop, with focus on EV power adjustment time and precision are evaluated and compared. Technically response time is the major factor for grid service provision as response precision always improves with aggregation of multiple vehicles. Typical inaccuracy of the response is about the step of $1 \mathrm{~A}$ only corresponds to approximately $230 \mathrm{~W}$ in power, which is below the accuracy limit of typical multi-hundred kilowatt response power for an ancillary service.

The control signal and response of the vehicle to the changes in the charging current limits are shown in Fig. 3, Fig. 4 and Fig. 5. The graphs are showing only the first 3 minutes of the experimental data to better appreciate the difference between the control and response.

As can be seen from the Figure, ramping speeds of the EV on phase 1 are different for up and down modulation. While

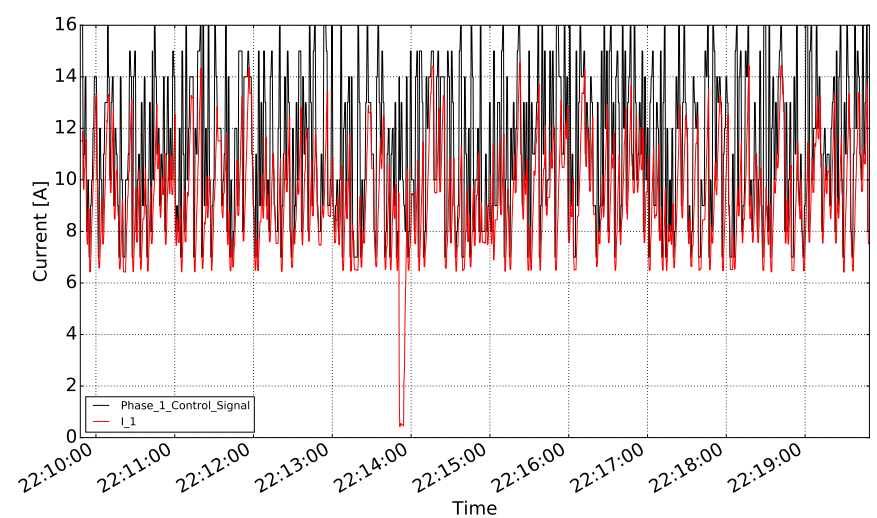

Fig. 3. Response timing EV 1

increasing the charging current to the new higher limit might take up to 3 seconds, decreasing the charging current to the lowered limit only takes up to 1 second.

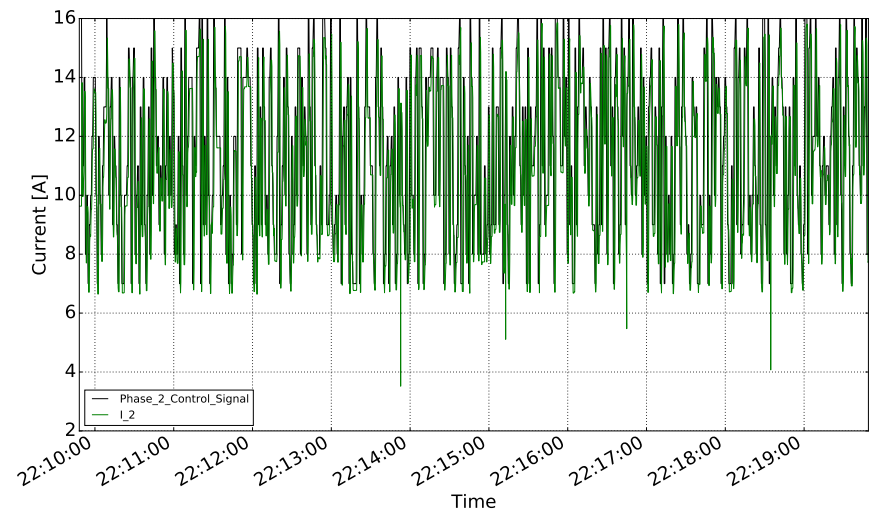

Fig. 4. Response timing EV 2

The EV on phase 2 has much faster ramping rates. Both up and down modulation of charging current is performed in under 500 milliseconds.

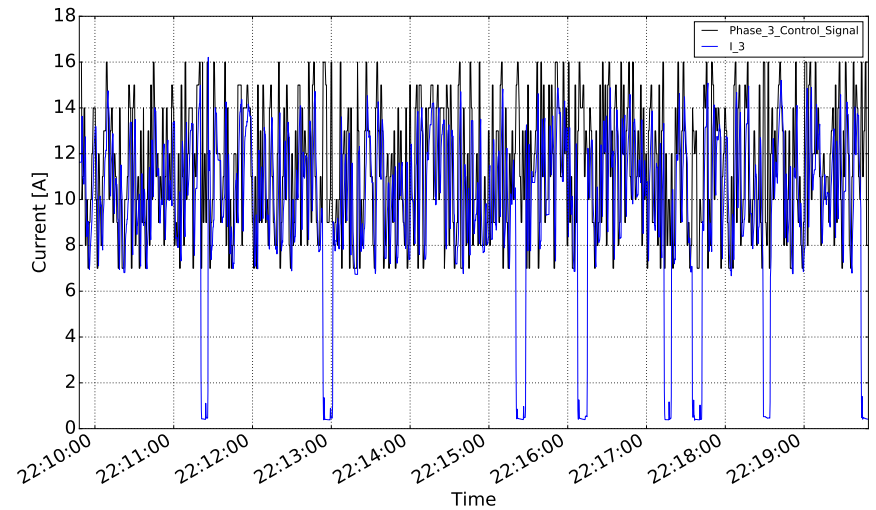

Fig. 5. Response timing EV 3 
Lastly, EV on phase 3 has a bit slower ramping rates up and down. It takes up to 2 seconds to lower the charging current and up to 3 seconds to increase the charging current to the higher limit. Additionally, as can be noted in the figure, the EV also shows occasional current drop to under $1 \mathrm{~A}$ for a about 5 seconds, which could affect the quality of the provided service. This drop could be caused by the battery management system balancing the battery cell voltages or for cooling.

The timing performance of $3 \mathrm{EVs}$ is summarized in Table II.

TABLE I

SUMMARY OF EV RESPONSE TIMING

\begin{tabular}{|c|c|c|c|}
\hline EV nr. & Minimum & Average & Maximum \\
\hline $\mathbf{1}$ & $0.5 \mathrm{~s}$ & $1.0 \mathrm{~s}$ & $2 \mathrm{~s}$ \\
\hline $\mathbf{2}$ & $0.2 \mathrm{~s}$ & $0.3 \mathrm{~s}$ & $0.5 \mathrm{~s}$ \\
\hline $\mathbf{3}$ & $1 \mathrm{~s}$ & $2.5 \mathrm{~s}$ & $3 \mathrm{~s}$ \\
\hline
\end{tabular}

While all EVs are well within the IEC 61851 standard for charging current regulation, EV 1 and 3 have similar response times closer to a few seconds, where EV 2 stands out by having sub-second response time. Such difference in timing can be explained by advancement in power electronics of the EV chargers as EVs 1 and 3 are 5 years old and EV 2 is recently produced 2015 model.

To better compare the response of 3 EVs, zoomed in view of the control and response all 3 vehicles is shown in Fig. 6 .

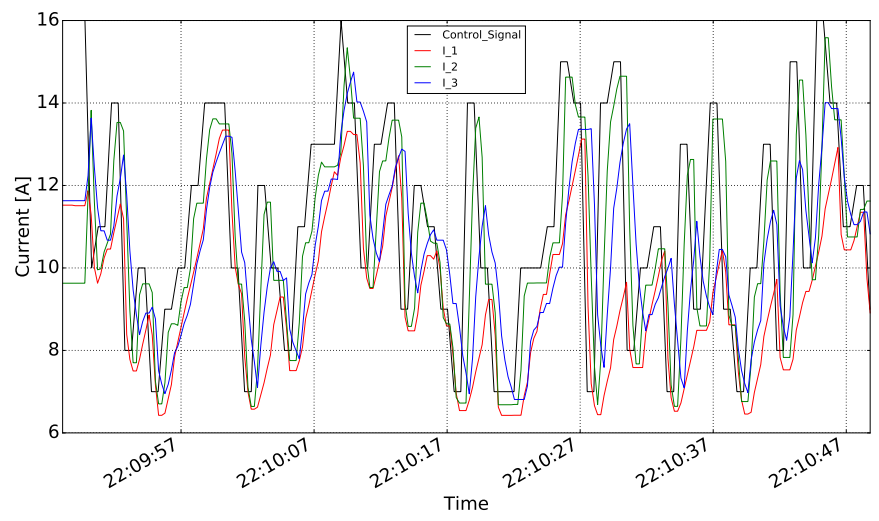

Fig. 6. Response precision comparison of all 3 EVs

TABLE II

CORRELATION BETWEEN CONTROL SIGNAL AND MEASURED RESPONSE

\begin{tabular}{|c|c|c|c|}
\hline EV nr. & $\mathbf{1}$ & $\mathbf{2}$ & $\mathbf{3}$ \\
\hline Correlation & 0.56 & 0.73 & 0.23 \\
\hline
\end{tabular}

EV suitability for providing grid services is summarized in Table III.

As shown in the results Section IV the EV response time to a control signal is quite fast. All EVs are suitable for performing even very fast frequency regulation. However only recently produced EVs with sub-second response times have potential
TABLE III

SUMMARY OF EV ABILITY TO PROVIDE FAST GRID SERVICES

\begin{tabular}{|c|c|c|c|c|c|}
\hline $\begin{array}{c}\text { EV } \\
\text { nr. }\end{array}$ & $\begin{array}{c}\text { Primary } \\
\text { Reserve }\end{array}$ & $\begin{array}{c}\text { Normal } \\
\text { Operation } \\
\text { Reserve }\end{array}$ & $\begin{array}{c}\text { Disturbance } \\
\text { Reserve }\end{array}$ & $\begin{array}{c}\text { Fast } \\
\text { Frequency } \\
\text { Reserve }\end{array}$ & $\begin{array}{c}\text { Synthetic } \\
\text { Inertia }\end{array}$ \\
\hline $\mathbf{1}$ & + & + & + & + & - \\
\hline $\mathbf{2}$ & + & + & + & + & + \\
\hline $\mathbf{3}$ & + & + & + & + & - \\
\hline
\end{tabular}

to provide the synthetic inertia service. That is partly due to good adherence to IEC 61851 charging standard. The standard specifies the response time to be below 3 seconds, however as shown, recently produced EVs can throttle the charging current in less than a second.

All tests were performed in SYSLAB - a DTU research facility for intelligent, active and distributed power systems. SYSLAB is located at DTU Ris $\varnothing$ campus and is a part of the PowerLabDK experimental facilities.

\section{DISCUSSION}

This evaluation provides a realistic analysis of currently available EV readiness to provide grid services now and the near future.

While response time of the EVs is quite suitable for even fast grid services, they also have a few problems that might influence the quality of the delivered service. One such problem is inability of some EVs to resume the charging process after charging process was interrupted by disabling and re-enabling the charging spot. Another potential quality influencing problem is fluctuating undershoot of the EV charging current response to the limit set from the charging spot, typically the undershooting is up to $1 \mathrm{~A}$.

While proportional control of EV charging seems to be suitable for providing grid services it does not account for the efficiency of the EV charger [14]. This can be improved by charging the bulk of the aggregated EVs at maximum power and using only a few in proportional control to get a precise aggregated response. Another possible obstacle for grid service provision is $6 \mathrm{~A}$ minimum charging rate as defined in IEC 61851. If $6 \mathrm{~A}$ charging is too much for some application, the charging could also be disabled and then re-enabled when needed. However, the speed of re-enabling the charging process is rather slow and takes multiple seconds. Some vehicles even require physical re-plugging of the charging cable or door opening to continue charging, which interferes with user comfort.

While this work only considered AC charging control, developments are being made to provide grid services using external V2G chargers utilizing CHAdeMO fast charging protocol, that was extended to support bidirectional power flow. In that case the power response depends on the ramping rate of the $\mathrm{V} 2 \mathrm{G}$ charger as the EV is only utilized as a battery. A barrier for commercial grid service provision is incomplete communication protocols that lack information objects or 
response speed for this task. An EV communication standard IEC 15118 that extends IEC 61851 by adding high level communication and necessary information objects enabling the EVs to provide grid services.

\section{REFERENCES}

[1] P. Tielens and D. Van Hertem, "Grid inertia and frequency control in power systems with high penetration of renewables," Young Researchers Symposium in Electrical Power Engineering, pp. 1-6, 2012.

[2] A. Ulbig, T. S. Borsche, and G. Andersson, "Impact of low rotational inertia on power system stability and operation," IFAC Proceedings Volumes (ifac-papersonline), Ifac Proceedings Volumes, Ifac Proc. Vol. (ifac-papersonline), vol. 19, pp. 7290-7297, 2014.

[3] G. Delille, B. Francois, and G. Malarange, "Dynamic Frequency Control Support by Energy Storage to Reduce the Impact of Wind and Solar Generation on Isolated Power System's Inertia," IEEE Transactions on Sustainable Energy, vol. 3, no. 4, pp. 931-939, Oct 2012.

[4] K. Clement-Nyns, E. Haesen, and J. Driesen, "The impact of charging plug-in hybrid electric vehicles on a residential distribution grid," Power Systems, IEEE Transactions on, vol. 25, no. 1, pp. 371-380, Feb 2010.

[5] W. Kempton and J. Tomić, "Vehicle-to-grid power implementation: From stabilizing the grid to supporting large-scale renewable energy," Journal of Power Sources, vol. 144, no. 1, pp. 280 - 294, 2005.

[6] M. Marinelli, S. Martinenas, K. Knezović, and P. B. Andersen, "Validating a centralized approach to primary frequency control with seriesproduced electric vehicles," Journal of Energy Storage, vol. 7, pp. 63 73, 2016.

[7] P. Andersen, M. Marinelli, O. Olesen, C. Andersen, G. Poilasne, B. Christensen, and O. Alm, "The nikola project intelligent electric vehicle integration," Proceedings of ISGT 2014, 2014.

[8] K. Knezovic, M. Marinelli, P. Andersen, and C. Træholt, "Concurrent provision of frequency regulation and overvoltage support by electric vehicles in a real danish low voltage network," Proceedings of IEEE International Electric Vehicle Conference 2014, 2014.

[9] IEC TC69, "IS 61851-1:2010 Ed. 2.0," IEC Standard, 2010.

[10] H. Lund and W. Kempton, "Integration of renewable energy into the transport and electricity sectors through $\{\mathrm{V} 2 \mathrm{G}\}$," Energy Policy, vol. 36, no. 9, pp. 3578 - 3587, 2008.

[11] "Ancillary services to be delivered in Denmark Tender conditions," Tech. Rep. October, 2012.

[12] P. Hintjens, ZeroMQ: Messaging for Many Applications. O'Reilly Media, 2013.

[13] S. Martinenas, M. Marinelli, P. Andersen, and C. Træholt, "Implementation and demonstration of grid frequency support by $\mathrm{v} 2 \mathrm{~g}$ enabled electric vehicle," Proceedings of the 49th International Universities Power Engineering Conference (UPEC), 2014, pp. 1-6, 2014.

[14] A. Kieldsen, A. Thingvad, S. Martinenas, and T. Sørensen, "Efficiency test method for electric vehicle chargers," Proceedings of EVS29 International Battery, Hybrid and Fuel Cell Electric Vehicle Symposium, 2016. 